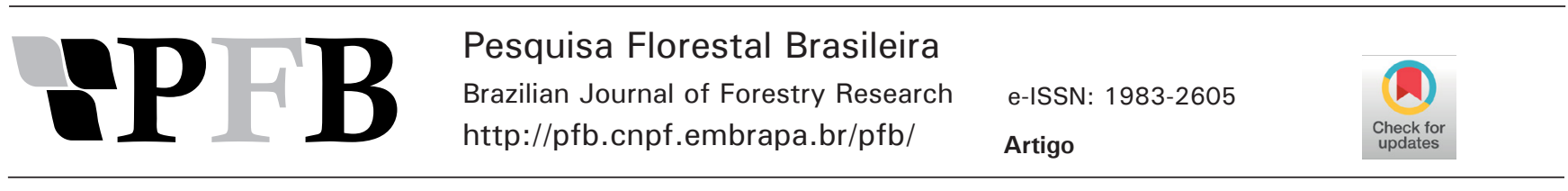

\title{
Caracterização química e atividade alelopática do óleo essencial de folhas de Blepharocalyx salicifolius
}

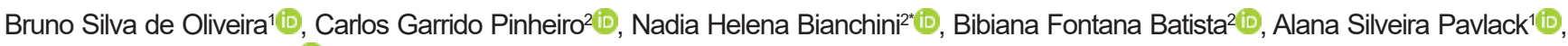 \\ Berta Maria Heinzmann², 3 (iD
}

${ }^{1}$ Universidade Federal de Santa Maria, Centro de Ciências Rurais, Departamento de Ciências Florestais, CEP 97105-900, Santa Maria, RS, Brasil

Universidade Federal de Santa Maria, Programa de Pós-Graduação em Engenharia Florestal, CEP 97105-900, Santa Maria, RS, Brasil

${ }^{3}$ Universidade Federal de Santa Maria, Centro de Ciências da Saúde, Departamento de Farmácia Industrial, CEP 97105-900, Santa Maria, RS, Brasil

*Autor correspondente:

nhbianchini@gmail.com

Termos para indexação:

Extrato de origem vegetal

Composição química

Alelopatia

Index terms:

Plant extracts

Chemical composition

Allelopathy

Histórico do artigo:

Recebido em 21/08/2019

Aprovado em 13/08/2021

Publicado em 13/12/2021
Resumo - No presente trabalho foi avaliada a composição química e atividade alelopática do óleo essencial (OE) de folhas de Blepharocalyx salicifolius (Kunth) O. Berg sobre a germinação e crescimento inicial de plântulas de Lactuca sativa L. (dicotiledônea) e de Sorghum bicolor (L.) Moench (monocotiledônea). O OE foi obtido por meio de hidrodestilação por $3 \mathrm{~h}$. A análise da composição do $\mathrm{OE}$ foi feita por cromatografia gasosa acoplada a um espectrômetro de massas (CG-EM). A atividade alelopática do extrativo foi avaliada nas concentrações de 2,5; 5,0 e 7,5\%. As sementes foram imersas nas soluções por 2 min e então foram distribuídas em placas de Petri. As placas foram mantidas em câmara incubadora BOD. No sétimo dia, foram avaliadas as variáveis germinação $(\%)$ e comprimento de raízes $(\mathrm{cm})$, da parte aérea $(\mathrm{cm})$ e total da plântula $(\mathrm{cm})$. Os constituintes majoritários identificados no OE foram eucaliptol $(49,6 \%)$, limoneno $(13,6 \%)$ e $\beta$-cariofileno $(12,2 \%)$. O OE afetou negativamente a porcentagem de germinação das sementes de L. sativa e os parâmetros sistema radicular e plântula total de $S$. bicolor. A atividade alelopática do OE foi negativa para as duas espécies avaliadas.

\section{Chemical characterization and alelopatic activity of essential oil of leaves of Blepharocalyx salicifolius}

\begin{abstract}
In the present study we evaluated the chemical composition and allelopathic activity of the essential oil (EO) of Blepharocalyx salicifolius (Kunth) O. Berg leaves on the germination and initial growth of Lactuca sativa L. (dicotyledonous) and Sorghum bicolor (L.) Moench (monocotyledon). EO was obtained by hydrodistillation for $3 \mathrm{~h}$. The EO composition analysis was performed by gas chromatography coupled to a mass spectrometry (GC-MS). The allelopathic activity of EO was evaluated at 2.5; 5.0 and $7.5 \%$. The seeds were immersed in the solution for 2 min., distributed in Petri dishes, that were maintained in a BOD incubator. On the seventh day, the variables germination $(\%)$, root length $(\mathrm{cm})$, shoot length $(\mathrm{cm})$ and total seedling length $(\mathrm{cm})$ were evaluated. The major constituents identified in the OE were eucalyptol (49.6\%), limonene (13.6\%) and $\beta$-caryophyllene (12.2\%). The EO affected negatively the germination percentage of $L$. sativa seeds and the root system and total seedling length of $S$. bicolor. There was a negative allelopathic activity against the two evaluated species.
\end{abstract}




\section{Introdução}

A utilização dos produtos florestais não madeireiros (PFNM) vem ganhando cada vez mais espaço no setor florestal, sendo utilizados para produção de cosméticos, medicamentos, resinas, gomas e fibras para a construção civil, indústria de perfumaria e de produtos de limpeza, entre outros fins (Fiedler et al., 2008). Os PFNM são de grande importância socioeconômica para o setor florestal, sendo possível destacar os óleos essenciais (OEs), cujo interesse internacional vem crescendo a cada ano (Santos et al., 2003).

Os OEs são constituídos por compostos orgânicos e voláteis (Nerio et al., 2010). O local de produção e secreção de OEs varia de acordo com a família das espécies. Dessa forma, os OEs podem ocorrer em tricomas glandulares, que são definidos como estruturas secretoras especializadas, distribuídos em diferentes partes das plantas, como as folhas e as flores (Iriti et al., 2006; Siqueira et al., 2007; Nerio et al., 2010).

A alelopatia é considerada por muitos autores como a capacidade de plantas implicarem ações direta ou indiretamente a outras plantas, sendo que esta interação pode ser benéfica ou prejudicial (Taiz \& Zeiger, 2004). Esta influência se dá pela produção de substâncias químicas, denominadas aleloquímicos, que podem tanto estimular quanto inibir o desenvolvimento e o crescimento das espécies que estão expostas a estas substâncias (Magiero et al., 2009).

A atividade fitotóxica de extratos de Blepharocalyx salicifolius (Kunth) O. Berg (Myrtaceae) já foi descrita na literatura, como efeito fitotóxico do extrato aquoso de suas folhas (Imatomi et al., 2015), a atividade de extratos de acetato de etila e hexânico de cascas e folhas (Habermann et al., 2015), além do extrato de acetato de etila fracionado de folhas (Habermann et al., 2017). Isto corrobora o potencial desta espécie para a produção de substâncias herbicidas naturais. No entanto, não foram encontrados relatos científicos da atividade alelopática do $\mathrm{OE}$ de $B$. salicifolius sobre a germinação e crescimento inicial de plântulas.

Nesse sentido, este estudo tem como propósito avaliar o potencial alelopático do óleo essencial (OE) de folhas de $B$. salicifolius sobre a germinação e crescimento inicial de plântulas. Foram testadas sementes de alface (Lactuca sativa L.) como dicotiledônea, enquanto que o sorgo (Sorghum bicolor (L.) Moench) foi a monocotiledônea inserida no bioensaio.

\section{Material e métodos}

O material vegetal foi coletado no município de Santa Maria, RS, durante o verão. O óleo essencial (OE) de Blepharocalyx salicifolius (Kunth) O. Berg foi obtido pela hidrodestilação de folhas frescas fracionadas (aproximadamente $500 \mathrm{~g}$ por repetição), em aparelho Clevenger, por $3 \mathrm{~h}$, em triplicata. O extrativo foi armazenado a $-4{ }^{\circ} \mathrm{C}$, em frasco âmbar vedado.

A análise da composição química foi feita por cromatografia gasosa, em um cromatógrafo gasoso AGILENT 7890A acoplado a um espectrômetro de massas AGILENT 5975C. Utilizou-se uma coluna capilar de sílica fundida DB-5MS $(30 \mathrm{~m}$ x $0,25 \mathrm{~mm}$ $\mathrm{x} 0,25 \mu \mathrm{m})$, com volume de injeção $1,0 \mu \mathrm{L}$; gás

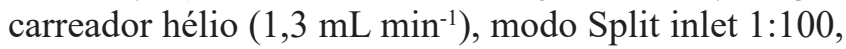
com temperatura do injetor e detector de $250{ }^{\circ} \mathrm{C}$ e $320^{\circ} \mathrm{C}$, respectivamente. Os constituintes do $\mathrm{OE}$ foram identificados através da comparação do índice de Kovats (IK) e dos padrões de fragmentação dos espectros de massas com o banco de dados do equipamento (NIST, 2009) e com dados da literatura (Adams, 2009). A quantificação dos componentes individuais do $\mathrm{OE}$ foi obtida por cromatograma de íons totais.

\section{Análise da atividade alelopática}

Foram utilizadas sementes de alface (Lactuca sativa L.), cultivar veneranda, e sorgo (Sorghum bicolor (L.) Moench), representantes, respectivamente, de espécies dicotiledôneas e monocotiledôneas. As sementes das duas espécies foram adquiridas em comércio varejista no município de Santa Maria, RS. A escolha das espécies bioindicadoras se baseou em estudo já reportado na literatura (Tomaz et al., 2014).

As sementes de alface não precisaram passar pelo processo de assepsia, pois vieram acondicionadas em envelopes fechados, não tendo contato com patógenos ou outras substâncias. As sementes de sorgo, que foram adquiridas a granel, foram submetidas à assepsia para eliminação de possíveis organismos patogênicos, segundo metodologia adaptada de Pinheiro et al. (2016).

Segundo Coutinho et al. (2000), um dos produtos mais utilizados para realizar assepsia é o hipoclorito de sódio ( $\mathrm{NaClO})$, que quando aplicado em concentração e tempo adequados auxilia na eliminação de contaminantes e organismos patogênicos. As sementes foram submersas em solução de $\mathrm{NaClO} 2 \%$ por 2 min. Após, foram 
filtradas em peneira e armazenadas em béquer até o início do experimento.

As sementes das duas espécies foram submetidas às concentrações de $2,5 \% ; 5,0 \%$ e 7,5\% de OE, além de um tratamento controle, composto apenas por água destilada (CA), e um controle negativo, composto pelos diluentes $(\mathrm{CN})$. Todos os tratamentos tiveram 4 repetições. Para cada repetição foram selecionadas 25 sementes de cada espécie, segundo metodologia adaptada de Pinheiro et al. (2017).

As soluções dos cinco tratamentos foram preparadas separadamente em um béquer, acrescentando-se $0,1 \%$ de Tween ${ }^{\circledR} 20$, água destilada, $0,9 \%$ de etanol e o OE para atingir as concentrações de $2,5 \% ; 5,0 \%$ e $7,5 \%$ do extrativo, de acordo com o tratamento. O CA foi composto de $5 \mathrm{~mL}$ de água destilada e o $\mathrm{CN}$, de água destilada, $0,9 \%(45 \mu \mathrm{L})$ de etanol e $0,1 \%(5 \mu \mathrm{L})$ de Tween $^{\circledR}$ 20. Para os demais tratamentos, as soluções foram preparadas de modo que, para cada tratamento, $o$ volume total da solução onde as sementes foram imersas fosse de $5 \mathrm{~mL}$. As sementes foram imersas nas soluções por 2 min e em seguida foram acomodadas em placas de Petri de $9 \mathrm{~cm}$ de diâmetro, contendo discos de papel filtro umedecido com $2 \mathrm{~mL}$ de água destilada (Pinheiro et al., 2017).

As placas de Petri foram acondicionadas em sacos plásticos, sendo posteriormente transferidas para uma câmara de germinação BOD a $25^{\circ} \mathrm{C}( \pm 1)$, com fotoperíodo programado em escuro/claro $(12 \mathrm{~h} \mathrm{/12} \mathrm{h).}$ Ao final do sétimo dia de incubação, foram consideradas sementes germinadas aquelas com emissão de epicótilo maior que $2 \mathrm{~mm}$ (Pinheiro et al., 2017).

Para as sementes de sorgo, acrescentou-se, no quarto dia do experimento, $1 \mathrm{~mL}$ de água destilada em cada placa de Petri. Esta etapa foi necessária, pois constatou-se durante o período de incubação, nos testes de viabilidade, um grande consumo de água para a germinação das sementes.

Ao final do experimento, foram avaliadas as variáveis germinação $(\%)$ e comprimento de parte aérea $(\mathrm{cm})$, do sistema radicular $(\mathrm{cm})$ e total da plântula $(\mathrm{cm})$. Os resultados foram submetidos ao teste de normalidade e homogeneidade de variâncias. Como não atingiram os pressupostos, foram analisados por meio do teste Kruskal-Wallis, no software ActionStat.

\section{Resultados}

\section{Composição química}

O óleo essencial (OE) de folhas frescas de Blepharocalyx salicifolius apresentou rendimento de $2,3 \%$ e densidade de $0,9 \mathrm{~g} \mathrm{~mL}^{-1}$. Foram identificados 21 constituintes (Tabela 1), representando 94,6\% da composição total. Os componentes majoritários do OE foram o eucaliptol (sinônimo: 1,8-cineol; 49,6\%), limoneno (13,6\%), $\beta$-cariofileno (12,2\%) e o $\alpha$-terpineol $(2,1 \%)$. Os demais constituintes identificados ficaram com percentuais abaixo de $2 \%$.

Tabela 1. Composição química do óleo essencial de Blepharocalyx salicifolius (Kunth) O. Berg.

Table 1. Chemical composition of the essential oil of Blepharocalyx salicifolius (Kunth) O. Berg.

\begin{tabular}{|c|c|c|c|}
\hline Constituintes & $\mathbf{I K}_{\text {calc. }}$ & $\mathbf{I K}_{\text {tab. }^{*}}$ & $\begin{array}{c}\text { Cromatograma de } \\
\text { íons totais } \\
(\%)\end{array}$ \\
\hline$\alpha$-Pineno & 931 & 931 & 1,58 \\
\hline$\beta$-Pineneo & 974 & 975 & 0,27 \\
\hline$\beta$-Myrceno & 991 & 988 & 1,35 \\
\hline$\alpha$-Phellandreno & 1003 & 1005 & 0,99 \\
\hline Limoneno & 1027 & 1028 & 13,64 \\
\hline Eucaliptol & 1029 & 1031 & 49,61 \\
\hline$E$ - $\beta$-Ocimeno & 1049 & 1050 & 0,26 \\
\hline$\gamma$-Terpineno & 1058 & 1064 & 1,08 \\
\hline Linalol & 1101 & 1101 & 0,48 \\
\hline Terpinen-4-ol & 1177 & 1180 & 1,07 \\
\hline$\alpha$-Terpineol & 1190 & 1190 & 2,14 \\
\hline$\alpha$-Copaeno & 1377 & 1372 & 0,30 \\
\hline$\beta$-Cariofileno & 1421 & 1415 & 12,19 \\
\hline Seychelleno & 1440 & 1448 & 0,51 \\
\hline$\alpha$-Cariofileno & 1455 & 1451 & 1,71 \\
\hline$\gamma$-Muuroleno & 1478 & 1474 & 0,78 \\
\hline$\alpha$-Muuroleno & 1482 & 1481 & 0,48 \\
\hline$\beta$-Eudesmeno & 1488 & 1489 & 0,59 \\
\hline Valenceno & 1497 & 1495 & 1,22 \\
\hline$\delta$-Cadineno & 1509 & 1519 & 1,12 \\
\hline$\alpha$-Amorfeno & 1516 & 1519 & 0,56 \\
\hline
\end{tabular}

Onde: IKcalc. e IK tab. - índices de Kovats calculado e tabelado, respectivamente. Fonte: Nist (2009). 


\section{Atividade alelopática}

Não foi observada diferença significativa entre os tratamentos quando analisada a atividade alelopática em relação à variável porcentagem de sementes de $S$. bicolor germinadas (Figura 1). No entanto, em sementes de L. sativa os tratamentos com as concentrações de $5,0 \%$ e 7,5\% de OE apresentaram diferença significativa, quando comparados com o controle com água (CA) e o controle negativo $(\mathrm{CN})$. A germinação das sementes de L. sativa apresentou redução na maior concentração de OE $(7,5 \%)$, observando-se $80 \%$ de sementes germinadas.
Não foram observadas diferenças significativas para comprimento da parte aérea $(p=0,4085)$, do sistema radicular $(p=0,1693)$ e total da plântula $(p=0,1360)$ de L. sativa (Figura 2) por atividade alelopática do OE.

Semelhante ao observado para $L$. sativa, o desenvolvimento da parte aérea de $S$. bicolor não diferiu entre os tratamentos $(p=0,0831)$ em relação à atividade alelopática do OE (Figura 3). No entanto, para o sistema radicular e plântula total, todos os tratamentos com $\mathrm{OE}$ $(2,5 \% ; 5,0 \%$ e $7,5 \%$ de OE) diferiram significativamente do $\mathrm{CA}$ e do $\mathrm{CN}$.

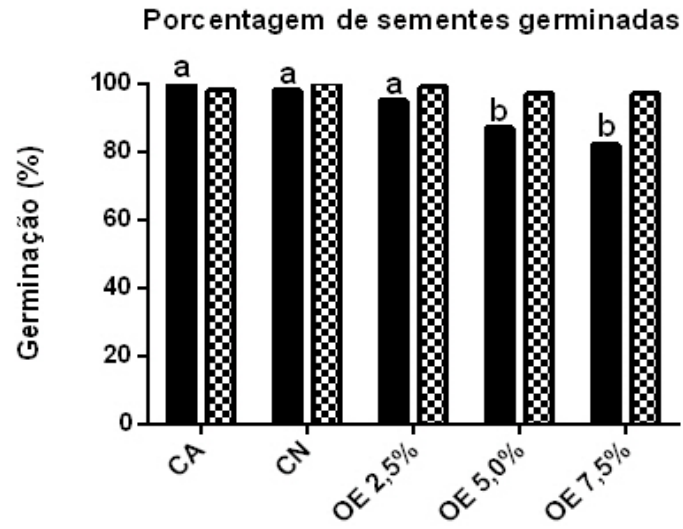

Figura 2. Efeito alelopático do óleo essencial de Blepharocalyx salicifolius (Kunth) O. Berg $(\mathrm{n}=4)$ em Lactuca sativa. $\mathrm{CA}=$ controle de água; $\mathrm{CN}=$ controle negativo; $\mathrm{OE}=$ óleo essencial em diferentes concentrações. Médias seguidas pela mesma letra não diferem estatisticamente $(p \geq 0,05)$.

Figure 2. Allelopathic effect of the essential oil of Blepharocalyx salicifolius (Kunth) O. Berg $(\mathrm{n}=4)$ in Lactuca sativa. $\mathrm{CA}=$ water control; $\mathrm{CN}$ $=$ negative control; $\mathrm{OE}=$ essential oil in different concentrations. Means followed by the same letter do not differ statistically $(p \geq 0.05)$.
Figura 1. Porcentagem de sementes germinadas de Sorghum bicolor e Lactuca sativa nos tratamentos com óleo essencial (OE) de Blepharocalyx salicifolius (Kunth) O. Berg $(\mathrm{n}=4)$. CA = controle de água; $\mathrm{CN}=$ controle negativo. Médias seguidas por letras diferentes indicam diferenças significativas $(p<0,05)$.

Figure 1. Percentage of germinated seeds of Sorghum bicolor and Lactuca sativa in treatments with essential oil (EO) of Blepharocalyx salicifolius (Kunth) O. Berg ( $=4)$. $\mathrm{CA}=$ water control; $\mathrm{CN}=$ negative control. Means followed by different letters indicate statistical differences $(p<0.05)$.

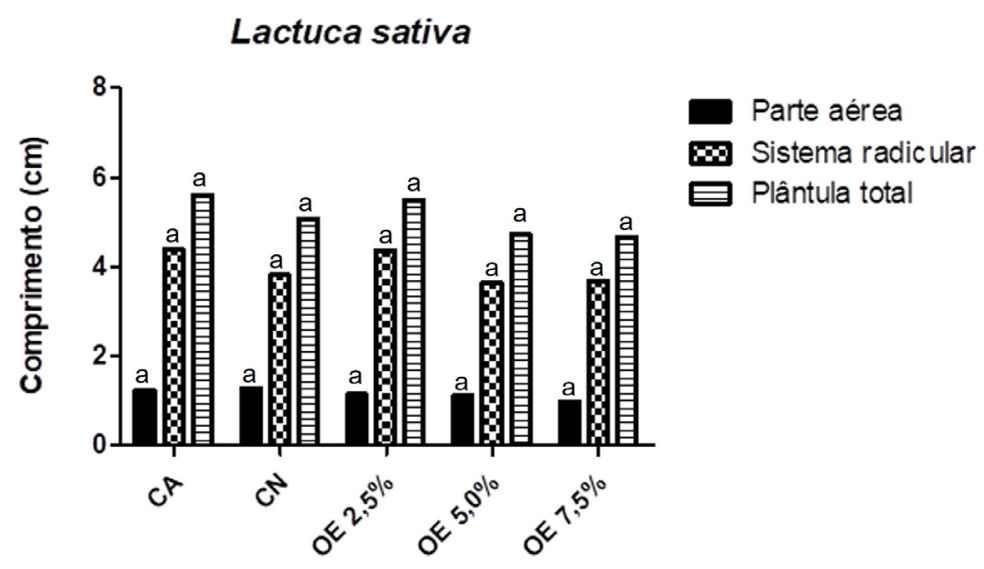




\section{Sorghum bicolor}

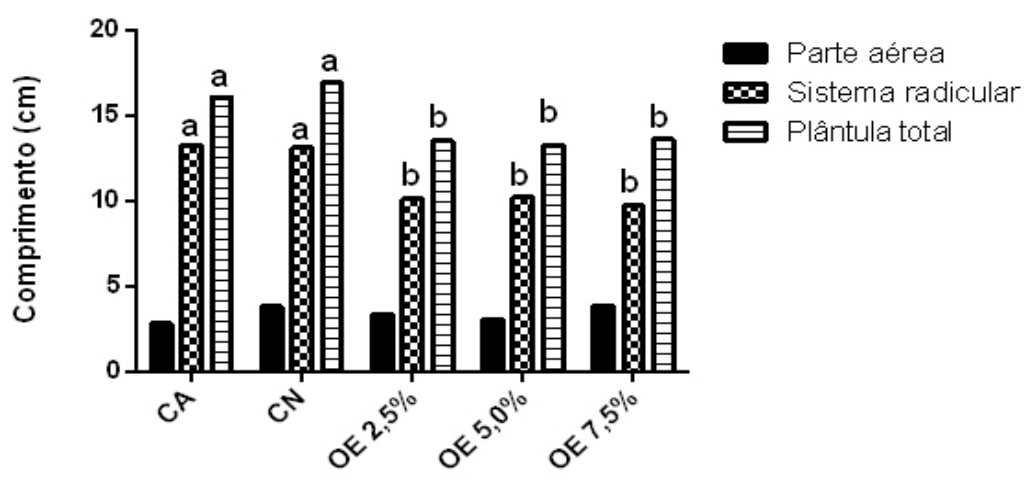

Figura 3. Efeito alelopático do óleo essencial de Blepharocalyx salicifolius (Kunth) O. Berg $(\mathrm{n}=$ 4) em Sorghum bicolor. $\mathrm{CA}=$ controle de água; $\mathrm{CN}=$ controle negativo; $\mathrm{OE}=$ óleo essencial em diferentes concentrações. Médias seguidas por letras diferentes indicam diferenças estatísticas $(p$ $<0,05)$.

Figure 3. Allelopathic effect of the essential oil of Blepharocalyx salicifolius (Kunth) O. Berg (n $=4$ ) in Sorghum bicolor. $\mathrm{CA}=$ water control; $\mathrm{CN}$ $=$ negative control; $\mathrm{OE}=$ essential oil in different concentrations. Means followed by different letters indicate statistical differences $(p<0.05)$.

\section{Discussão}

A análise da composição química do óleo essencial (OE) de folhas de Blepharocalyx salicifolius indicou diferenças em comparação ao estudo de Godinho et al. (2014), onde para essa mesma espécie identificaram 22 constituintes químicos, perfazendo $97,82 \%$ da composição química total, sendo os compostos majoritários $\alpha$-Eudesmol (47,65\%), $\gamma$-Eudesmol (31,1\%), Elemol (7,29\%) e Globulol (1,7\%). De acordo com Sharifi-Rad et al. (2017), diferenças na composição química, considerando os constituintes majoritários entre as duas análises, podem estar relacionadas a fatores genéticos e ambientais, como solo, clima, nutrientes e habitat. Além disso, esses autores indicam que fatores como a estação do ano, dia e horário em que foi realizada a coleta também podem influenciar tanto a composição quanto o rendimento do $\mathrm{OE}$.

Um dos principais objetivos da avaliação da atividade alelopática é a redução do uso de herbicidas sintéticos nos cultivos agrícolas, substituindo-os por alternativas naturais. Uma alternativa é o uso de OEs para combater o crescimento de plantas daninhas, que causam prejuízos em culturas agrícolas, principalmente anuais, uma vez que substâncias naturais são menos agressivas ao meio ambiente e aos seres humanos e animais (Carvalho et al., 2002; Santos et al., 2004). Neste sentido, os OEs destacam-se como possíveis bioherbicidas naturais, podendo ser eficazes como inibidores na germinação e no desenvolvimento de plantas daninhas (Duke et al., 2002).

Observando-se a atividade alelopática do $\mathrm{OE}$ de $B$. salicifolius, merece destaque o perfil diferenciado da sua ação frente a mono e dicotiledôneas. Considerando Lactuca sativa, os resultados encontrados indicaram apenas uma variação negativa para a variável germinação nas duas maiores concentrações avaliadas. Entretanto, para Sorghum bicolor, a germinação não foi afetada, tendo sido observada uma influência negativa sobre o desenvolvimento inicial de plântulas, também nas duas maiores concentrações avaliadas.

Segundo Habermann et al. (2015), os extratos acetato de etila de cascas e folhas de $B$. salicifolius e o extrato hexânico de cascas inibiram o crescimento de Echinochloa crus-galli e Euphorbia heterophylla. Adicionalmente, Habermann et al. (2016) descreveram que o extrato acetato de etila de folhas $B$. salicifolius inibiram o alongamento dos coleóptilos de Triticum aestivum, além de alterar o tempo médio de germinação e reduzir a massa seca e o crescimento de Sesamum indicum. $\mathrm{O}$ extrato aquoso de folhas da mesma espécie apresentou atividade fitotóxica frente a sementes de E. heterophylla; Ipomoea grandifolia e E. crus-galli (Imatomi et al., 2015), e o extrato acetato de etila fracionado de folhas também apresentou potencial para produção de herbicidas naturais (Habermann et al., 2017).

Yoshimura et al. (2011) realizaram estudos com o eucaliptol, constituinte majoritário isolado no controle da proliferação e alongamento de células de tabaco, detectando sua inibição. Também relataram que a taxa de germinação de sementes de tabaco caiu para $60 \%$ a uma concentração de $1.000 \mu \mathrm{M}$ deste constituinte. Além disso, Suttle et al. (2016) relataram a inibição no brotamento de tubérculos de Solanum tuberosum pelo eucaliptol e o envolvimento da inibição da síntese ou ação de giberelinas no efeito observado. As giberelinas têm como função regular o crescimento, alongamento do caule, germinação, floração, brotação de folhas, frutos e senescência celular (Taiz \& Zeiger, 2004). 
O eucaliptol e o limoneno, dois dos constituintes majoritários do OE de B. salicifolius, também apresentaram efeitos inibitórios sobre o desenvolvimento celular e redução fotossintética da alga Chlorella vulgaris (Zhao et al., 2016). Segundo os mesmos autores, estes compostos são liberados por cianobactérias no meio aquático. A inibição do crescimento celular da alga foi maior com o aumento da concentração do limoneno, e as células íntegras foram mortas pela concentração de $4 \mathrm{mM}$ deste constituinte. Ao mesmo tempo, uma redução na absorção da radiação nos comprimentos de onda correspondentes aos pigmentos fotossintéticos, de 413 , 433, 457 e 663 nm, foi detectada, indicando a degradação desses pigmentos na alga. Mais uma evidência desse efeito foi o desaparecimento da xantofila, observado com o tratamento de 1,6 $\mathrm{mM}$ de limoneno. Quando C. vulgaris foi tratada com eucaliptol e limoneno, foi observado um comprometimento do fotossistema II. Entre outros efeitos, os compostos avaliados promoveram a dissipação da energia luminosa absorvida na forma de calor. Portanto, eucaliptol e limoneno produzidos por cianobactérias podem desempenhar papéis alelopáticos, induzindo a degradação de pigmentos e reduzindo a capacidade fotossintética em algas. No entanto, não foram localizados estudos destes constituintes isolados sobre a fotossíntese de plantas superiores. Assim, sugerese que pesquisas nesse sentido sejam realizadas, tanto sobre cultivos agrícolas quanto sobre espécies florestais.

Para ß-cariofileno, outro dos componentes majoritários do $\mathrm{OE}$ de B. salicifolius, também são encontrados registros de evidências de atividade alelopática na literatura. Segundo Sánchez-Muñoz et al. (2012), o ß-cariofileno apresentou inibição do alongamento radicular das plântulas de Physalis ixocarpa nas concentrações de 50 e $150 \mu \mathrm{g} \mathrm{mL}^{-1}$, enquanto que em Echinochloa crus-galli só houve inibição com 150 $\mu \mathrm{g} \mathrm{mL}^{-1}$. Além disso, o ß-cariofileno também inibiu a biomassa seca de plantas de P. ixocarpa cultivadas por 18 dias anteriores ao tratamento. Experimentos in vivo indicaram que esse constituinte $(100 \mu \mathrm{g} \mathrm{mL}-1)$ teve um grande efeito $72 \mathrm{~h}$ após o tratamento em folhas de plantas de $P$. ixocarpa, inibindo o fotossistema II e também induzindo a clorose nas folhas tratadas. Adicionalmente, Wang et al. (2010) relataram a produção de elevadas concentrações de $\beta$-cariofileno, classificado como composto fitotóxico, por Mikania micrantha, uma das piores espécies invasoras do mundo, em resposta a elevadas concentrações de $\mathrm{CO}_{2}$ na atmosfera, aumentando assim o seu potencial invasor.

\section{Conclusões}

O óleo essencial (OE) de Blepharocalyx salicifolius apresentou como componente majoritário o eucaliptol (1,8-cineol). Adicionalmente, o efeito alelopático do OE foi diferenciado sobre as espécies alvo deste estudo, havendo uma atividade negativa em comparação com os tratamentos controle.

Embora não tenham sido encontrados trabalhos relatando o efeito alelopático do OE de B. salicifolius, os dados encontrados na literatura para vários de seus componentes majoritários isolados indicam que a inibição da germinação de L. sativa e do crescimento inicial de plântulas de $S$. bicolor resultou do efeito combinado de diferentes constituintes presentes nesse extrativo.

O efeito alelopático de B. salicifolius foi detectado apenas em concentrações de $5 \%$ e superior. Por isso, recomenda-se que novos testes sejam realizados para avaliação de atividades inseticidas e antimicrobianas e da viabilidade econômica em concentrações mais baixas do que as testadas nesse estudo para o extrativo avaliado.

\section{Referências}

Adams, R. P. (ed.) Identification of essential oil components by gas chromatrography/quadrupole mass spectroscopy. Carol Stream: Allured Business Media, 2009. 804 p.

Carvalho, G. J. et al. Potencial alelopático do feijão de porco (Canavalia ensiformes) e da mucuna preta (Stilozobiumaterrimum) no controle da tiririca (Cyperusrotundus). Ciência e Agrotecnologia, v. 26, n. 3, p. 647-651, 2002.

Coutinho, W. M. et al. Efeito de hipoclorito de sódio na germinação de conídios de alguns fungos transmitidos por sementes. Fitopatologia Brasileira, v. 25, n. 3, p. 552-555, 2000.

Duke, S. O. et al. Chemical from nature for weed management. Weed Science, v. 50, n. 2, p. 138-151, 2002. https://doi:10.1614/00431745(2002)050[0138:ipcfnf]2.0.co;2.

Fiedler, N. C. et al. Produtos florestais não madeireiros: importância e manejo sustentável da floresta. Revista Ciências Exatas e Naturais, v. 10, n. 2, 2008.

Godinho, W. M. et al. Volatile constituents from leaves of Blepharocalyx salicifolius (Kunth) O. Berg (Myrtaceae). Boletin Latinoamericano y del Caribe de Plantas Medicinales y Aromaticas, v. 13, p. 249-253, 2014. 
Habermann, E. et al. Atividade fitotóxica de cascas do caule e folhas de Blepharocalyx salicifolius (Myrtaceae) sobre espécies infestantes. Acta Biológica Colombiana, v. 20, n. 1, p. 153-162, 2015. http:// dx.doi.org/10.15446/abc.v20n1.42756.

Habermann, E. et al. Phytotoxic potential of young leaves from Blepharocalyx salicifolius (Kunth) O. Berg (Myrtaceae). Brazilian Journal of Biology, v. 76, n. 2, p. 531-538, 2016. http://dx.doi. org/10.1590/1519-6984.24114.

Habermann, E. et al. In vitro herbicide activity of crude and fractionated leaf extracts of Blepharocalyx salicifolius (Myrtaceae). Brazilian Journal of Botany, v. 40, n. 1, p. 33-40, 2017. http:// dx.doi.org/ 10.1007/s40415-016-0317-4.

Imatomi, M. et al. Phytotoxic effects of aqueous leaf extracts of four Myrtaceae species on three weeds. Acta Scientiarum, v. 37, n. 2, p. 241-248, 2015. http://dx.doi.org/10.4025/actasciagron.v37i2.19079.

Iriti, M. et al. Histo-cytochemistry and scanning electron microscopy of Lavender glandular trichomes following conventional and microwave-assisted hydrodistillation of essential oils: a comparative study. Flavour and Fragrance Journal, v. 21, p. 704-712, 2006. https://doi.org/10.1002/ffj.1692.

Magiero, E. C. et al. Efeito alelopático de Artemisia annua L. na germinação e desenvolvimento inicial de plântulas de alface (Lactuca sativa L.) e leiteiro (Euphorbia heterophylla L.). Revista Brasileira de Plantas Medicinais, v. 11, n. 3, p. 317-324, 2009.

Nerio, L. S. et al. Repellent activity of essential oils: a review. Bioresource Technology, v. 101, p. 372-378, 2010. https://doi. org/10.1016/j.biortech.2009.07.048.

Nist. National Institute of Standards and Technology (U.S.). NIST/ EPA/NIH mass spectral library \& search program. Hoboken: John Wiley \& Sons, 2009.

Pinheiro, C. G. et al. Efeito da assepsia superficial na germinação e incidência de fungos em sementes de espécies florestais. Pesquisa Florestal Brasileira, v. 36, n. 87, p. 253-260, 2016. https://doi. org/10.4336/2016.pfb.36.87.1234.

Pinheiro, C. G. et al. Essential oil of the Brazilian native species Hesperozygisringens: a potential alternative to control weeds. Journal of Essential Oil-Bearing Plants, v. 20, p. 701-711, 2017. https://doi.org/10.1080/0972060X.2017.1319297.

Sánchez-Muñoz, B. A. S. et al. The sesquiterpenes $\beta$-caryophyllene and caryophyllene oxide isolated from Senecio salignus act as phytogrowth and photosynthesis inhibitors. Molecules, v. 17, p. 1437-1447, 2012. https://doi.org/10.3390/molecules 17021437.
Santos, A. J. et al. Produtos não madeireiros: Comercialização, classificação, valoração e mercados. Revista Floresta, v. 33, n. 2, p. 215-224, 2003. http://dx.doi.org/10.5380/rf.v33i2.2275.

Santos, C. C. et al. Efeito de extratos orgânicos, associados ao surfactante TWEEN 80, na germinação e crescimento de plântulas de alface. Ciência e Agrotecnologia, v. 28, n. 2, p. 296-299, 2004. https://doi.org/10.1590/S1413-70542004000200007.

Sharifi-Rad, J. et al. Biological activities of essential oils: from plant chemoecology to traditional healing systems. Molecules, v. 22, n. 1, p. 1-55, 2017. https://doi.org/10.3390/molecules22010070.

Siqueira, A. A. et al. Avaliação da atividade antibacteriana do óleo essencial de Eucalyptus globulus: uma alternativa aos antibióticos convencionais. Scientia: Revista do Centro Universitário Vila Velha, v. 8, p. 199-214, 2007.

Suttle, J. C. et al. The involvement of gibberellins in 1,8-cineolemediated inhibition of sprout growth in russet burbank tubers. American Journal of Potato Research, v. 93, p. 72-79, 2016. https://doi.org/10.1007/s12230-015-9490-4.

Taiz, L. \& Zeiger, E. Fisiologia vegetal. Porto Alegre: Artmed, 2004. 719 p.

Tomaz, M. A. et al. Composição química e atividade alelopática do óleo essencial de eucalipto. Bioscience Journal, v. 30, p. 475-483, 2014.

Wang, R. L. et al. Responses of Mikania micrantha, an invasive weed to elevated $\mathrm{CO}_{2}$ : induction of $\beta$-caryophyllene synthase, changes in emission capability and allelopathic potential of $\beta$-caryophyllene. Journal of Chemical Ecology, v. 36, p. 1076-1082, 2010. https:// doi.org/10.1007/s10886-010-9843-x.

Yoshimura, H. et al.1,8-Cineole inhibits both proliferation and elongation of by-2 cultured tobacco cells. Journal of Chemical Ecology, v. 37, p. 320-328, 2011. https://doi.org/10.1007/s10886011-9919-2.

Zhao, J. et al. Inhibitory effects of eucalyptol and limonene on the photosynthetic abilities in Chlorella vulgaris (Chlorophyceae). Phycologia, v. 55, n. 6, p. 696-702, 2016. http://dx.doi. org/10.2216/16-38.1. 